\title{
Sexual Assault against Children from the Perspective of Students in Ajloun University College/University of Balqa Applied
}

\author{
Safia M. Jabali ${ }^{1}$ \\ ${ }^{1}$ Education College, Zarka National University, Zarka, Jordan \\ Correspondence: Safia. M. Jabali, Education College, Zarka National University, Zarka, Jordan.
}

Received: August 13, 2015

Accepted: March 30, 2015

Online Published: April 24, 2015

doi:10.5539/jedp.v5n1p148

URL: http://dx.doi.org/10.5539/jedp.v5n1p148

\begin{abstract}
This study investigates the major causes of sexual assault against children and certain demographic variables affecting these factors. A 24-item Questionnaire of four variables has been developed. It includes the family, social and religious, media, psychic and individual factors. The study involved a sample of (100) students, randomly chosen. The study shows that leaving the children with the house-maid is one of the major causes of sexual crimes against children, in addition to the abused use of the internet by the family members in the presence of children, weak religious drive of the youth besides depression cases in the adolescent stage besides attractive attributes in the aggressive person. The total score for the whole questionnaire was fair. There were statistically significance differences attributed to sex and age.
\end{abstract}

Keywords: sexual crimes against children, sexual harassment, sexual abuse against children, sexual violence against children

\section{Introduction}

The phenomenon of sexual harassment of children of new phenomena and alien to our society, are not considered born of the moment, but she woke up from her trance to knock alarm bells in many Muslim societies (Morsi, 2007) and increases the risk of this phenomenon on the children that in the first years of life are more sensitive and vulnerable to ill-treatment, and associated abuse in the early years of age peripheral psychological and physical especially if their bodies are still fragile and their bones Linh unbreakable and lack the possibility to choose the assistance of a number of alternatives offered by the adults, but they cannot distinguish the source of the abuse of the source of safety (Windham et al., 2004; Mathoma, Maripe-Perera, Khumalo, Mbayi, \& Seloiwe, 2006) And therefore considered child abuse from social and psychological problems that remain raised in the personality of the individual to the advanced stages of age. Placing it in the ranks of the difficult problems that require decisive confrontation by each family first and social welfare institutions and educational institutions, in order to determine the type of abuse, and the rate of spread, as a prelude to treat and to reduce the effects on the child's personality (Poulakou-Rebelakou, 2000). Due to the multiplicity of sources of child abuse has expanded the concept of abuse so that it includes physical abuse (punishment cruel suffering of the child physically especially beating that leaves the obvious effects in the body Kjerouh and bruises deep), sexual abuse and psychological abuse (which includes an insult to the child and ridicule him and his potential and exposed positions immoral Ktaati drug and cigarette smoking and commit behaviors requiring a decision by adults such as begging or theft ... etc.). This is why the development of an appropriate definition of the concept of child abuse and protection a central issue and the need for the service of the family that suffer from these problems (Wolf, 2005, p. 31) Valisaeh the child be difficult endless raised expire effects of the end of the act, but it is a dramatic event a continuing influence in the personality of the individual, therefore tried many researchers study the relationship between abuse early for the child and his behavior in later childhood, and found many of them significant relationship between the child's vulnerability to sexual abuse. The psychological and physical, by one or both parents, and between the emergence of many emotional problems and aggressive behavior and the persistent mistakes punishable by law (Wind et al., 2000). This is what draws attention to the need to assume that the social institutions and correctional institutions and the care and protection of children and their social roles in health and legal protection of children from falling victim to abuse and neglect (Macmillan, Jamison, \& Walsh, 2003). 


\subsection{Problem of the Study}

The problem with the study as a child more influential than any other natural persons for any attack my body or myself he cannot resistance because it does not have the strength and the will to deter the offender from committing the deed Almhaam and feeling frightened, especially if the families do not give it the attention and abusing him beatings and humiliation So this assault him the beginning of a hard life does not end.

\subsection{Questions of the Study}

The current study is trying to answer the main question follows:

What factors leading to sexual abuse against children?

Branching off from this main question is the following sub-questions:

(1) What family and social factors leading to sexual abuse against children?

(2) What factors due to the media and leading to sexual abuse against children?

(3) What religious factors leading to sexual abuse against children?

(4) What psychological factors and individual leading to sexual abuse against children?

(5) Is there a statistically significant factor for demographic variables (gender, age) from the viewpoint of the study sample with respect to areas of study?

\subsection{Importance of the Study}

The importance of this study, including the following:

(1) Try to access the results and practical solutions to the problem of the study, to help children from exposure to such abuse of various kinds.

(2) From this study, it is hoped that the results will help the process of social welfare institutions to address the multiple cases of violence against children, so as not to become one of the fiercest problems against the security of society and the development of the legal boundaries of its provisions, and a statement of jurisprudence.

(3) Focus on sexual harassment for children who are in the first years of life and the role of the family and their relationships and other factors in the spread in the Arab societies.

\subsection{Objectives of the Study}

Identify the factors leading to sexual abuse against children within their families a source of care and attention through.

(1) Knowledge of family and social factors leading to sexual abuse against children.

(2) Knowledge of the role of the media in the prevalence of sexual abuse against children.

(3) Knowledge of religious factors leading to sexual abuse against children.

(4) Knowledge of the psychological and individual factors leading to sexual abuse against children.

\subsection{Determinants of the Study}

This study is limited to:

Students Ajloun University College (BAU) in the academic year 2011/2012.

Operational definitions:

Crimes of sexual abuse: Is the exposure of children and adolescents Guerra to mature into sexual activities they do not understand and are in violation of their rights. (Mukhaimar \& Abdel, 2004)

Children: their children, whether they are male or female, between the ages of $6 / 15$ years of sexual abuse committed against them. (R. Klark \& Klark, 1989)

Theoretical framework and previous studies

First, the theoretical framework: Researchers briefed on a number of references relating to the sexual abuse of children by their importance to search.

The sexual assault on a child is to use the child to satisfy the sexual desires of an adult or a teenager. And exposed to any activity or sexual behavior and sexual harassment often includes the child, such as touching or coming into contact with him to the harasser sexually. In addition to other forms of sexual assault on a child 
sexual intercourse, child prostitution and sexual exploitation through pornography and pornographic sites. This has devastating emotional effects of the attack itself, which is a betrayal of the child and the betrayal of confidence by his authority and exploited it. (Mukhaimar \& Abdel, 2004)

And called the memos "sexual harassment sexual abuse" on each raised against the child/child deliberately, so the existence of the scenes obscene or sexual images or bare, and other stimuli Ktmay tentacles genitals or urged him to touch the members of the other person or his teaching bad habits - Kalastmina example - as well as sexual assault in direct forms known natural ones and anomalies. Can be defined as sexual harassment accordingly that: words and deeds and gestures beyond the scope of fitness issued from people mean from behind win over others to exercise their sexual behavior Kalmlamsh direct physical to the victim, or the use of body language; like looking at who comes out the bounds of decency (stare long), and winking eye, or use hand gestures or other organs of the body to express their sexual desires. May be that the threat or extortion or intimidation, which is a flagrant infringement on the freedom and dignity of others. It may be sexual harassment "by default" virtual, but in a different manner Klju actor to show (W) sensitive parts of the body, or display pictures and movies and pornography in front of his victims in order to induce them or influence them (Iman, 2005).

And images created for sexual harassment in the Saudi society, which could fall under psychological violence and sexual use some young men of the means of modern verticals including photography and Bluetooth and the Internet to take pictures and video clips of women or steal their photographs and Joalathen aim Aptzaizen and threatening to publish the pictures in the event of non-approval of that is asked of them; Kamraafqathm and out with them and maybe have sex at an advanced stage when the surrender of the offender and the victim Atbdi little resistance in order to avoid scandal or lack of existence of their self-help them to get rid of the problem, which fell victim to it. (Jardan, 2005, p. 9)

It takes several pictures of sexual harassment; such as using words and phrases and gestures nationality by the actor toward the student victim, and perhaps touching sensitive parts of his body, and harassing way reflect the desire to sexually Moaqath. May take the harassment image threat at a time tend the victim to avoid the complaint, for fear of the perpetrator or the scandal, especially in the case of females, which some studies suggest that only $4 \%$ of those who have been subjected to sexual harassment in their workplaces they voiced a complaint with refrained from complaining about $96 \%$ for several reasons, the foremost of the fear of loss of employment, and the scandal, and the vibration center in front of the victim's co-workers, or because the offender is the owner of the facility (Alrdien, 2008).

The sexual abuse of a form of child abuse that could be older adolescent or adult uses a child for sexual stimulation. Include or put pressure on the child to engage in sexual activities with a view to satisfy their sexual desires and the same sexual contact with children, or used in the production of child pornography (Badr, 2001).

\section{Statistics}

(1) Sexual harassment of children in Jordan: records show a clinic forensic that the number of cases that have been inspected during 1998 has reached 437 case, which included 174 case of sexual abuse on children and were classified as follows: 48 cases of sexual abuse was the aggressor where from within the family, and 79 cases of abuse Hitch assailant was known to the victim or a nearby neighbor or any other, and 47 cases of child abuse was where by a stranger.

(2) Sexual harassment of children in Lebanon: According to Dr. Bernard Gerbagh in 2000 that Almutmr fourth Lebanese to protect juveniles pointed to the high number of sexual assaults on minors, especially males of them at the hands of their relatives or minors aggressors.

(3) Sexual harassment of children in Egypt: Indicates the first study of incidents of children in Egypt prepared of Dr. Faten Abdel-Rahman Tnbara mentor media to assist in the Graduate Institute for Children at the University of Ain Shams that the incidents of sexual abuse of children, representing $18 \%$ of the total of the various incidents of the child. With regard to the perpetrator of the incident unrelated child victim, it was clear that the ratio is $35 \%$ he is a relative to children and $65 \%$ are not related to the child.

(4) Child abuse in Saudi Arabia: confirmed one of the studies conducted by the National Committee for the Prevention of Child Abuse. In Saudi Arabia, there are tens of thousands of children who are victims of severe trauma over the life as a result cause harm. It was found that there are $77 \%$ of the aggressors Hola Aldhaa boys' fathers and $11 \%$ of their relatives and more than $75 \%$ of abusers are people known to the victim child relationship bound together by kinship or knowledge. And sexual harassment, this one kind of mischief and note 
that most of the crimes of sexual abuse of children occur from relatives and friends is linked to our children. (Ministry of Interior) Although each case of individuality, but that there are quasi-public lead to the emergence of this disaster, including: 1) rash sexual in the media in all its forms and gluttony in eating, 2) absence of control parental, 3) overconfidence in some close to the child and leave them in isolation for observation, 4) fear of family. The scandal in the punishment of the offender, which leads to repeat his crime, 5) not to educate children about their bodies and how and when to treat the others with him, 6) lack of development of regulations, legal systems in some places to follow the shape of this crime and evaluated as worth, 7) children's fear of reporting, both of the family do not even considered a partner, or the capacity of offender and, of course, falls within the reasons the absence of commitment to religious and moral (Tnbara, 2003).

\subsection{Previous Studies}

Study Al Saud (2000) titled "The phenomenon of child abuse types, causes and characteristics of exposed him". The sample consisted of 182 of Almhnin of pediatricians and psychologists meetings and staff specialists and psychologists hospitals Riyadh. The results show that most types of physical abuse at a percentage of $91.5 \%$, followed by cases of neglect, $87.3 \%$, and psychological abuse, $53.5 \%$, and cases of sexual abuse of $46.5 \%$, then the cases of children who were exposed to more than one type of $16.9 \%$ and more child abusers are males increased by $67.6 \%$ and females at $63.4 \%$, and the mothers had registered more than an assault on their children increased by $74.6 \%$, then the parents of $73.2 \%$ and stepmother $50.7 \%$ and then the Worlds at home $33.8 \%$, and the brother of $23.9 \%$, followed by stepfather $19.7 \%$ and Sister $15.5 \%$ and uncles $5.6 \%$ and finally uncles $4.2 \%$ as explained results show that the reconstruction of the children who have been abused under two years by $66.2 \%$, then who is aged between $4-6$ years increased by $63.4 \%$, then the category of $6-8$ years increased by $54.9 \%$ in addition to the families of children who have been hurt characterized by disintegration, low income, and the father has more than one wife, and a low level of education of the parents.

Study Jishi (2001), a study entitled "The Reality of child abuse through the issues contained to the Ministry of the Interior in the period 1997-2000 of the State of Bahrain" aimed to account for all cases of children coming into the offices of women's police departments of security, during the period 1997-2000. The total number of cases received (262) case, divided into two types of sexual assault and physical, and the percentage of attacks on males $77 \%$ compared to females $23 \%$, and the sexual assaults by $64 \%$ of the attacks contained to the police station, and the percentage of males abused sexually $65 \%$ compared to females 35 , and most of the attacks on male outside the family, while the female sexual Onalaatdae was happening within the family.

Study Zahrani (2003) titled "The phenomenon of child abuse in Saudi society" and amounted to the same study, 2050 students aged between 10-17 years of Riyadh and Mecca, Dammam, and the study found the following results: the existence of child abuse in Saudi society, and half of the sample subjected to a form of abuse in their daily lives, and more types of abuse is psychological abuse, where the rate was $70 \%$, followed by physical abuse and accounted for $25.30 \%$ and $23.9 \%$ of negligence. The highest percentage of children have been abused are orphans, followed by cases where the parents are separated, then that will be Fahaallowaldan divorced, then where the parents are alive, Cases in which the deceased father, and their mother Odnahm deceased. Victims of abuse suffer from social and psychological problems, health, educational. Study Vigio Rideau and his colleagues (Figueiredo et al., 2004) a study entitled "The History of abuse in childhood with parents in Portugal" in order to know the prevalence of physical and sexual abuse in childhood with parents in Portugal. The sample consisted of (1000) one of them (506) of the mothers and the rest of Allaaba and completed all respondents answered all the Portuguese version of the questionnaire history of childhood. The results indicate the presence of the prevalence of a high physical ill-treatment of the sample where the level of prevalence in childhood (73\%) is that the rate of abuse -related injuries acute and bone fractures was weak where the prevalence rate $(9.5 \%)$ of the sample. Decided Subscribers to the physical abuse began before the age of 13 years. There were no differences in the ill-treatment between the sexes, while the rate of sexual abuse and much lower rate (2.6\%) of the total sample. And found a statistical relationship between the function of the intensity of abuse and lack of consolidation by the adults in adolescence, the researchers concluded that the rate of abuse in Portugal lowest rates that I've found studies that were used to identify the date of childhood in America and Spain.

Study Rodgers and others (Rodgers et al., 2004) study entitled "Determine the extent of Arrows five styles of patterns of abuse (sexual abuse, physical abuse, abuse emotional, physical neglect, emotional neglect) in health behavior in adults", the evaluation of exposure to a number from these patterns during childhood, and it has (221) woman from Mrakzasahh preliminary in San Ditjobamrica. Researchers used a scale of shock childhood to estimate exposure to abuse in childhood, and the information form to inquire about alcohol consumption and 
scale to evaluate appropriate behavior. It also showed a relationship between the statistical function of both physical and sexual abuse, emotional neglect and emotional childhood, on the one hand, and varying patterns of health behavior in adults on the other. The researchers found that women who have been subjected to multiple patterns of abuse in childhood were more likely to come back on alcohol Ommarsh deviant sexual behavior in adulthood. Study Pl Stone and his colleagues AL 2004, Gladstone's study entitled "Study of a single style of patterns of abuse, a pattern of sexual abuse" and considered it a shock of childhood trauma, the study aimed to describe clinical characteristics that Tmizalnads Almktibat with and without Altardilisaeh sex in childhood, and examined the relationship between sexual abuse in Mrahlhalotfolh and self-harm destination and violence in personal relationships, and the sample consisted of (25), a woman suffering from depression, and use them corresponding method and applied them to a questionnaire Altqriralmata and Mkieshamltunllaktiab Hamilton Depression. Results showed that women who had been sexually abused in childhood suffer from depression in adulthood and more prone to suicide and self-harm, and Taanielnads who have been sexually abused in childhood Oadaof Adtarabakulq and panic in adulthood, and that women who have been subjected to physical abuse and psychological was their fathers less warmer and attention, and suffering of women who have suffered sexual abuse in childhood characteristics of borderline personality and hysteria, the conflict parental childhood has been associated with abuse, emotional neglect and physical abuse, and the results showed Oada that women following have been subjected to sexual abuse in childhood to have a rise in the practice of the behavior of self-harm is meant in the past and more recently, though the shock early to have remained outstanding, which increased the difficulty of healing Manalaktiab.

Study Zahrani (2005) entitled "People kind of relationship abuse for the sexual abuse" although that (62.1) of subjects did not disclose them sexually abusive, the percentages were as those who: (16.6\%) of kin, and (12.4\%), friends, and (4.8\%), the Muslim Brotherhood, and (2.1\%) of teachers/parameters, and (1\%) mothers. Amaaldharb Although also of that (23.3\%) did not disclose Artkpo violence towards them, the percentages were as follows: $(29.4 \%)$ parents, and $(18.5 \%)$ brothers, and (11.6\%) relatives, and $(8.3 \%)$ mothers, and (5.5\%), friends, and (3.4) teachers/parameters. It showed that the causes of abuse paternal age Whenever father was a small age increased neglect of his children, as well as the work of the mother Vlomhat workers Aktrahmala for their children, housewives, as well as housing and family income and the greater the number of children for (6) the greater the likelihood of exposure of the child to neglect Almchaara and be the cause of the Abuse of Children. Study Chan and others (Chen, Dunne, \& Hana, 2006) study titled "Detect the prevalence of sexual abuse of children and its implications for the emergence of mental disorders and delinquent behavior among girls in China" study sample consisted of 354 female students from the medical school high school in Henan Province. The researchers used a resolution of inquiring indirectly from exposure to attitudes or experiences of unwanted sexual before the age of sixteen and depression and suicidal behavior and Alaztrapat behavioral grave has been found from the results of a study that one of every five girls $(21.9 \%)$ confirmed that it had been before the sixteenth Age to type at least one of the types of sexual abuse (class researchers to sexual harassment 12 species within the two areas of physical harassment and harassment of non-physical). While confirmed the girl and one of every seven girls she had been sexually abused, including physical harassment, researchers found no significant relationship between exposure to sexual abuse and variables educational level of the parents and the presence of the brothers, and accommodation in the countryside or in the city childhood. It showed a statistical relationship between the function of exposure to sexual abuse and some mental disorders, such as depression, and suicidal thinking and planning to commit suicide, drinking alcohol, smoking, and aggressive behavior. Study Said (2007) entitled "The detection rates exposure to physical abuse and sexual abuse in childhood among juvenile delinquents compared to a particular officer of the non-delinquent", the study sample consisted of 24 children from the juvenile delinquents living in a care home events Pudong ferrous and (24) of non-delinquents from my school revolution and Osama bin Zaid School for Boys. The researcher hired by identifying the experiences of abuse in childhood after undergoing some modifications. The study results showed that the presence of statistically significant differences between groups in physical abuse, both a father figure and a mother, or in the direction of juvenile delinquents. There was no statistically significant differences between the two groups in the sexual abuse, as was the prevalence of physical abuse (image of the Father and Mother image) and sexual abuse between juvenile delinquents $(16.67 \%)$ and $(25 \%)$ and $(29.17 \%)$, respectively, while the rates were Ancharha between members of the control sample (12.5\%) and (16.67\%) and (25\%), respectively. There was no correlation between the number of times a function of deposit in the care home on the one hand and physical abuse (image of the Father and Mother image) and sexual abuse on the other. Study algareeb (2007) entitled "Social and economic characteristics and cultural to the families of children exposed to abuse in Saudi society" study relied on the case study method for the analysis of (110) dossier of case files of children who have 
been subjected to abuse from several sources healthy, legal and social with a number of Saudi Arabian cities. The study found that physical abuse was ranked first, followed by emotional abuse, and psychological abuse, and in the last rank of sexual abuse. The ranking based Hoalab abuse against the child, then one of the brothers and mother, and the maid, and the driver. The study also found high abuse against children in the extended family, while less offending in nuclear families. And that the increase in the abuse of families, which is drawn from the (9-12 people), while less than a few families in size. The study found that the majority of abused children belonging to the families of matrimonial. The majority of families belonging to the rural and Bedouin style while carrying the families living in urban areas. The study also found that the more education Say Father increased to abuse committed against children, and with respect to increasing the level of economic abuse in families with low economic income, then in captivity with an average economic level. And less Alasralty infested are hurting families with higher economic level. Study of the cult, Abu Doh (2007) entitled "To examine the nature of acts of sexual harassment and public sexual harassment, incest, especially the children". This study aimed to find out the social dimensions associated with these acts within the contexts of varying the daily lives of women, children and access to the most important forms of sexual harassment within the contexts of social interaction between the female and the social environment surrounding the monitoring of the most important consequences resulting from exposure of female and male of any form of sexual harassment. Most important strategies which then Tpinha by victims to confront these acts all this, taking into account, inter interior elements, which control the situation in addition to the external elements which is made up of a group social and cultural conditions that frame the position of context, has revealed the results of the study on the fact that sexual harassment and its various forms phenomenon exists between the study sample and that $78.6 \%$ that recently witnessed increasing acts of sexual harassment against a female, also confirmed the results of the study to $62.1 \%$ of the study sample that all women and children vulnerable to harassment in the sense that these acts are no longer geared toward a certain segment of women only.

\subsection{What Distinguishes Our Study from Previous Studies}

Notes that progress from previous studies that addressed the issue of sexual abuse against children, whether studies of Arab or foreign It focused on the male and female, where she spoke of studies on family factors most impact on children and did not focus our study only on the factors of family, but also focused on religious factors, psychological and media the impact on children and commit sexual offenses against them by their relatives and others.

Has coincided studies study Zahrani (2005) and the study of the Al-Saud (2000), which emphasized that the more the aggressors on the child by relatives. And study Zahrani (2005), which confirmed the lack of disclosure of children from their attackers sexually by relatives. One of the main causes of abuse against a child young age of the father as a father was a small age increased to neglect his children.

\section{Systematic Study}

\subsection{Methodology of the Study}

Researchers follow the descriptive analytical method to conduct this study, so as to suitability of the nature of the study.

Population of the study: The study population consisted of students from the University of Balqa Applied Ajloun University College for the academic year 2011/2012 and totaling 200 students.

The study sample: The number of members of the community 100 students spread over three disciplines a child's upbringing/social service/psychological counseling Educational. The researchers chose a random sample of students from the specialty of child-rearing, social service and Educational Guidance. The number of respondents (100 students) and formed a rate (50\%) of the study, and Table (1) shows the distribution of the sample according to demographic characteristics: 
Table 1. Distribution of the sample according to demographic characteristics

\begin{tabular}{llll}
\hline Item & Group & Repetition & Percentage \\
\hline \multirow{3}{*}{ Depending on the variable sex } & Males & 37 & 24.5 \\
& Females & 114 & 75.5 \\
& Total & 151 & 100.0 \\
Qualification & B.Sc. & 62 & 41.1 \\
& Diploma & 89 & 58.9 \\
& Total & 151 & 100.0 \\
Specialization & Social service & 54 & 35.8 \\
& Psychological counseling and educational & 72 & 47.7 \\
& Child-rearing & 25 & 16.6 \\
Age & Total & 151 & 100.0 \\
& Less than 20 years old & 60 & 39.7 \\
& 21-30 years & 36 & 23.8 \\
& More than 30 years & 55 & 36.4 \\
The level of religiosity & Total & 151 & 100.0 \\
& Very religious & 37 & 24.5 \\
& Religious & 49 & 32.5 \\
& Not religious & 65 & 43.0 \\
& Total & 151 & 100.0 \\
\hline
\end{tabular}

Study tool:

Researchers using the descriptive method to prepare the survey questions to pose axes, which will depend upon resolution images and to identify the factors leading to sex crimes against children. Mraaadad questionnaire has the following steps:

(1) Identify the goal of the questionnaire in the light of the objective of the study.

(2) The researcher has developed a number of paragraphs on each of the sub-questions. Sual has reached the number of paragraphs of his image questionnaire elementary (31) is poor.

(3) The questionnaire has been his image initial Gentlemen arbitrators have asked them to amendment and addition or deletion of any provision they deem appropriate.

(4) Has been conducting the amendments requested by the arbitrators Gentlemen. The number of paragraphs of the questionnaire after adjustment (26) is poor and thus be in its final form questionnaire has achieved honesty internal and external honesty.

\subsection{The Stability Study Tool}

To make sure of the stability of the tool, researchers based method of testing and re-testing (test-re-test), as was the distribution of the tool (30) students from outside the study sample, and re-applied to them after two weeks, and then by Pearson correlation coefficient between the first application and the application second on the total score and each area of Aalostbana also been verified coefficient of internal consistency of the questionnaire on the total score and each of the fields of the six, and Table 2 below shows the coefficients stability of the tool by using the Pearson correlation coefficient, and transactions of internal consistency of the questionnaire method using equation Cronbach's alpha. 
Table 2. Coefficients stability of the tool and transactions of internal consistency of the questionnaire

\begin{tabular}{llll}
\hline No & Domain & Pearson correlation coefficients & Cronbach's alpha \\
\hline 1 & Family and social factors & 0.90 & 0.81 \\
2 & Factors media & 0.78 & 0.88 \\
3 & Religious factors & 0.84 & 0.90 \\
4 & Psychological factors & 0.79 & 0.95 \\
& Total score & 0.87 & 0.92 \\
\hline
\end{tabular}

Shown in Table (2) the transactions of the stability of the questionnaire using Pearson ranged from equation (0.78-0.90), and coefficients ranged from internal consistency of the questionnaire using Cronbach's alpha between equation (0.81-0.95), and all transactions were considered sufficient for the purposes of this study.

And judgment on the degree of importance of each and every problem areas and the problems of art education researcher used the following equation:

Were calculated how much each of these three levels according to the following equation:

Level $=$

Thus, the extent of each level is as follows:

-Be at a low level (1.33-2.33)

- Be at the average level (2.34-3.67)

-Be at the high level (3.68-5)

Results of the study

This chapter includes an overview of the results of the study by answering questions and as follows:

The results of the first question: What is the level of crimes of abuse against children in Jordan from the perspective of students Ajloun University College?

To answer this question were calculated averages and standard deviations, were identified Rank crimes of abuse against children in Jordan from the perspective of students Ajloun University College, and each area of study tool, shown in the Table (3) that.

Table 3. Averages and standard deviations, grade and degree crimes of abuse against children in Jordan, from the standpoint of Ajloun University College students in general and for each area of study tool in descending order

\begin{tabular}{llllll}
\hline No. & Domain & SMA & Standard deviation & Rank & The degree of the problem \\
\hline 4 & Psychological factors & 3.60 & 0.80 & 1 & Medium \\
2 & Factors media & 3.32 & 0.72 & 2 & Medium \\
3 & Religious factors & 3.03 & 0.92 & 3 & Medium \\
1 & Family and social factors & 2.82 & 0.85 & 4 & Medium \\
& Total score & 3.10 & 0.76 & & Medium \\
\hline
\end{tabular}

Notes from the Table (3) that the crimes of abuse against children in Jordan from the viewpoint of students Ajloun University College in general (total score) was moderate, reaching the arithmetic average (3.10) and standard deviation (0.80), and came all areas of study tool moderately, ranging averages between (3.60-2.82), 
and came in first level domain "psychological factors", with a mean (3.60), and moderately and a standard deviation (0.80), and came in second order "field" factors media "with a mean (3.32) and moderately, and a standard deviation (0.72), and came in the rank third and penultimate field of" religious factors, with a mean (3.03) and moderately, and a standard deviation (0.92), and came in rank fourth and final area of "family factors and social" with a mean (2.82) and moderately, and a standard deviation (0.85) as for the paragraphs of each of the results were as follows:

(1) The area of "family and social factors"

Was calculated averages and standard deviations, were identified grade and degree crimes of abuse against children in Jordan from the viewpoint of students Ajloun University College, the paragraphs of this area, and the table shows (4) that.

Table 4. Averages and standard deviations, grade and degree crimes of abuse against children in Jordan from the viewpoint of students Ajloun University College of paragraphs of the field of "family and social factors" in descending order

\begin{tabular}{llllll}
\hline No. & Paragraph & SMA & $\begin{array}{l}\text { Standard } \\
\text { deviation }\end{array}$ & Rank & Degree \\
\hline 1 & Children left at home alone with the nanny & 3.05 & 1.03 & 1 & Medium \\
8 & Lack of sex education for children at a young age & 2.99 & 1.25 & 2 & Medium \\
5 & Not to isolate the boy about the girl in bed & 2.93 & 1.31 & 3 & Medium \\
3 & Failure to provide social support for children & 2.79 & 1.15 & 4 & Medium \\
6 & $\begin{array}{l}\text { Parents talk about sex (courtship) in front of children } \\
2\end{array}$ & 2.79 & 1.29 & 4 & Medium \\
4 & $\begin{array}{l}\text { Participation of children in the bed of parents } \\
\text { children }\end{array}$ & 2.78 & 1.09 & 6 & Medium \\
7 & $\begin{array}{l}\text { Dysfunctional family relationships } \\
\text { Total score }\end{array}$ & 2.66 & 1.32 & 7 & Medium \\
& & 2.57 & 1.27 & 8 & Medium \\
\hline
\end{tabular}

Notes from the Table (4) that the crimes of abuse against children in Jordan from the viewpoint of students Ajloun University College of vertebrae field of "family factors and social" in general (total score) were medium reaching the arithmetic average (2.82) and moderately and a standard deviation (0.85), came all the paragraphs of this area in the middle class, ranging between averages (3.05-2.57), and came in first order of paragraph (1) "leave the children at home alone with the nanny". A mean (3.05) and the high degree and a standard deviation (1.03), and came in second order "paragraph (8)" non-sexual education for children at a young age. With a mean (2.99) and the high degree and a standard deviation (1.25), and came in Rank penultimate paragraph (4) "the practice of parents for the behavior of some sex in front of children." My average (2.66) and a medium degree and a standard deviation (1.32), and came in the last paragraph Rank (7) "dysfunctional family relationships." My average (2.57) and the high degree and a standard deviation (1.27).

(2) Field "factors that are due to the media"

Was calculated averages and standard deviations, were identified grade and degree crimes of abuse against children in Jordan from the viewpoint of students Ajloun University College, the paragraphs of this area, and the table shows (5) that. 
Table 5. Averages and standard deviations, grade and degree crimes of abuse against children in Jordan from the viewpoint of students Ajloun University College of paragraphs of the field, "the factors that attributed to the media" in descending order

\begin{tabular}{|c|c|c|c|c|c|}
\hline No. & Paragraph & SMA & $\begin{array}{l}\text { Standard } \\
\text { deviation }\end{array}$ & Rank & Degree \\
\hline 10 & Parents use the internet in front of children & 3.91 & 0.93 & 1 & High \\
\hline 9 & Movies and sexually exciting cultural & 3.80 & 1.19 & 2 & High \\
\hline 11 & $\begin{array}{l}\text { Lack of control of parents to their children } \\
\text { when they are exposed to the media }\end{array}$ & 3.36 & 1.25 & 3 & Medium \\
\hline 13 & $\begin{array}{l}\text { Video clips and songs downlink and children } \\
\text { left unsupervised }\end{array}$ & 2.83 & 1.28 & 4 & Medium \\
\hline \multirow[t]{2}{*}{12} & $\begin{array}{l}\text { Internet and displays it from pornographic } \\
\text { sites and scenes }\end{array}$ & 2.71 & 1.34 & 5 & Medium \\
\hline & Total score & 3.32 & 0.72 & & Medium \\
\hline
\end{tabular}

Notes from the Table 5 that the crimes of abuse against children in Jordan from the viewpoint of students Ajloun University College of vertebrae field "factors that are due to the media" in general was moderate, reaching the arithmetic average (3.32) and moderately and a standard deviation (0.72), came paragraphs of this area in the class of high- and medium-ranged averages between (3.91-2.71), and came in first order, paragraph (10) "misuse of parents online in front of children," a mean (3.91) and the high degree and a standard deviation (0.93), and came in the second level, "paragraph (9)" movies and exciting cultural sexually "with a mean (3.80) and the high degree and a standard deviation (1.19), and came in Rank penultimate paragraph (13)" video clips and songs downlink and children left unsupervised. "With a mean (2.83) and a medium degree and a standard deviation (1.28), and came in the last paragraph Ran (12) "presented by the Internet and the sites and pornographic scenes" with a mean (2.71) and a medium degree and a standard deviation (1.34).

(3) The field of "religious factors"

Was calculated averages and standard deviations, were identified grade and degree crimes of abuse against children in Jordan from the viewpoint of students Ajloun University College, the paragraphs of this area, and the table shows (6) that.

Table 6. Averages and standard deviations, grade and degree crimes of abuse against children in Jordan from the viewpoint of students Ajloun University College of paragraphs of the field of "religious factors" in descending order

\begin{tabular}{|c|c|c|c|c|c|}
\hline No. & Paragraph & SMA & $\begin{array}{l}\text { Standard } \\
\text { deviation }\end{array}$ & Rank & Degree \\
\hline 14 & $\begin{array}{l}\text { The weakness of the religious faith of young people } \\
\text { who engage in sexual abuse against children }\end{array}$ & 3.44 & 1.12 & 1 & Medium \\
\hline 15 & Lack of attention to religious Blanch inside the house & 3.30 & 1.08 & 2 & Medium \\
\hline 16 & $\begin{array}{l}\text { The failure of the educational institutions for the } \\
\text { purpose of religious values in children }\end{array}$ & 3.17 & 1.13 & 3 & Medium \\
\hline 18 & The proliferation of cafes and cabarets Forbidden & 2.97 & 1.19 & 4 & Medium \\
\hline \multirow[t]{2}{*}{17} & The lack of deterrent penalties for homosexuality & 2.24 & 1.17 & 5 & Medium \\
\hline & Total score & 3.03 & 0.92 & & Medium \\
\hline
\end{tabular}


Notes from the Table (6) that the crimes of abuse against children in Jordan from the viewpoint of students Ajloun University College of vertebrae field "study plan" in general (total score) was moderate, reaching the arithmetic average (3.03) and a medium degree and a standard deviation (0.92), came paragraphs of this area Baldrjtin medium, ranging averages between (3.44-2.24), and came in first order, paragraph (14) "weak religious morals among young people who engage in sexual abuse against the child." With a mean (3.44) and a medium degree and a standard deviation (1:12), and came in second order "paragraph (15)" lack of interest Baltncih religious inside the house. With a mean (3.30) and the high degree and a standard deviation (1.08), and came in Rank penultimate paragraph (18) "The spread of cafes and cabarets Forbidden" average My Account (2.97) and a medium degree and a standard deviation (1.19), and came in the last paragraph Rank (17) "lack of deterrent penalties for homosexuality" a mean (2.24) and a medium degree and a standard deviation (1.17).

(4) The area of "psychological factors"

Was calculated averages and standard deviations, were identified grade and degree crimes of abuse against children in Jordan from the viewpoint of students Ajloun University College, the paragraphs of this area, and the table shows (7) So.

Table 7. Averages and standard deviations, grade and degree crimes of abuse against children in Jordan from the viewpoint of students Ajloun University College of paragraphs of the field of "psychological factors" in descending order

\begin{tabular}{lllllc}
\hline No. & Paragraph & SMA & $\begin{array}{l}\text { Standard } \\
\text { deviation }\end{array}$ & Rank & Degree \\
\hline 21 & Depressive symptoms associated with teen & 4.05 & 1.07 & 1 & High \\
22 & $\begin{array}{l}\text { The presence of positive characteristics in the } \\
\text { child's personal aggressor }\end{array}$ & 3.84 & 1.19 & 2 & High \\
23 & Weakness of empathy and relationships with others & 3.64 & 0.90 & 3 & Medium \\
20 & Automatic suppression of feelings and emotions & 3.45 & 1.43 & 3 & Medium \\
19 & Compulsive tendency to adventure and frustration & 3.07 & 1.14 & 5 & Medium \\
& Total score & 3.60 & 0.80 & & Medium \\
\hline
\end{tabular}

Notes from the Table (7) that the crimes of abuse against children in Jordan from the viewpoint of students Ajloun University College of vertebrae field of "psychological factors" in general was moderate, reaching the arithmetic average (3.60) and moderately and a standard deviation (0.80), and came all the paragraphs of this area between the high degree and medium ranged averages calculations between (05/04 to 07/03), and came level the first paragraph (21) "depressive symptoms associated with adolescence," a mean (4.05) and a high degree, and a standard deviation (1.07), and came in second order paragraph (22). The presence of the characteristics of positive personal aggressor on the child "with a mean (3.84) and the high degree and a standard deviation (1.19), and came in Rank penultimate paragraph (20)" to suppress feelings automatic and agitation "with a mean (3.45) and a medium degree and a standard deviation (1.14), and came in the last paragraph Rank (19)" compulsive tendency to adventure and frustration. My average (3.07) and a medium degree and a standard deviation (0.80). The results of the second question: Is there a statistically significant difference in the significance level (0.05) in the crimes of abuse against children in Jordan from the viewpoint of students Ajloun University College due to the variable sex.

To answer this question were calculated averages and standard deviations crimes of abuse against children in Jordan from the perspective of students Ajloun University College, has also been used test " $T$ " for two independent samples to examine differences according to gender, and Table 3 shows the results. 
Table 8. Averages and standard deviations and test t-test for independent samples of the differences in the crimes of abuse against children in Jordan from the perspective of students Ajloun University College, according to sex

\begin{tabular}{lllllll}
\hline Domain & Gender & Number & SMA & SD & Value T. & The significance \\
\hline Family and social & Males & 37 & 3.4358 & .71724 & $* 5.570$ & .000 \\
factors & Females & 114 & 2.6195 & .79204 & & \\
Factors media & Males & 37 & 3.8757 & .61165 & $* 5.947$ & .000 \\
& Females & 114 & 3.1439 & .66226 & & \\
Religious factors & Males & 37 & 3.5730 & .67026 & $* 4.405$ & .000 \\
& Females & 114 & 2.8474 & .92528 & & \\
Psychological factors & Males & 37 & 4.1676 & .54673 & $* 5.232$ & .000 \\
& Females & 114 & 3.4351 & .79166 & & \\
Total score & Males & 37 & 3.7630 & .56938 & $* 5.742$ & .000 \\
& Females & 114 & 3.0115 & .72644 & & \\
\hline
\end{tabular}

\subsection{Statistically Significance}

The results indicate in the Table (3) the presence of statistically significant differences at the level $(0.05 \geq)$ in the crimes of abuse against children in Jordan from the perspective of students of the Faculty of Ajloun university depending on the sex of the instrument as a whole and to all fields, and return these differences in favor of male students.

The results of the third question: Is there a statistically significant difference in the significance level $(0.05)$ in the crimes of abuse against children in Jordan from the viewpoint of students Ajloun University College due to the variable Qualification

To answer this question were calculated averages and standard deviations crimes of abuse against children in Jordan from the perspective of students Ajloun University College, has also been used test " $T$ " for two independent samples to examine the differences depending on the variable qualification, and the table shows (4) that.

Table 9. Averages and standard deviations in the crimes of abuse against children in Jordan from the perspective of students Ajloun University College depending on the variable Qualification

\begin{tabular}{lllllll}
\hline Domain & Qualification & Number & SMA & SD & Value T. & The significance \\
\hline \multirow{2}{*}{ Family and social factors } & B.Sc. & 62 & 3.28 & 0.94 & $* 6.300$ & 0.000 \\
& Diploma & 89 & 2.50 & 0.60 & & \\
Factors media & B.Sc. & 62 & 3.71 & 0.60 & $* 6.132$ & 0.000 \\
& Diploma & 89 & 3.05 & 0.68 & & \\
Religious factors & B.Sc. & 62 & 3.61 & 0.77 & $* 7.642$ & 0.000 \\
& Diploma & 89 & 2.62 & 0.80 & & \\
Psychological factors & B.Sc. & 62 & 4.02 & 0.83 & $* 5.745$ & 0.000 \\
& Diploma & 89 & 3.33 & 0.65 & & \\
Total score & B.Sc. & 62 & 3.67 & 0.70 & $* 7.172$ & 0.000 \\
& Diploma & 89 & 2.87 & 0.63 & & \\
\hline
\end{tabular}


Notes from the Table (4) the presence of statistically significant differences at the level $(0.05 \geq)$ in the crimes of abuse against children in Jordan from the viewpoint of students Ajloun University College depending qualified scientific instrument as a whole and on all fields, and return these differences for the benefit of undergraduate students.

The results of the fourth question: Are there statistically significant differences in the significance level $(0.05)$ in the crimes of abuse against children in Jordan from the viewpoint of students Ajloun University College attributable to specialize?

To answer this question were calculated averages and standard deviations crimes of abuse against children in Jordan from the perspective of students Ajloun University College variable depending on the specialty, and the table shows (5) that.

Table 10. Averages and standard deviations in the crimes of abuse against children in Jordan from the perspective of students Ajloun University College, depending on the variable of specialization

\begin{tabular}{lllll}
\hline Domain & Qualification & Number & SMA & SD \\
\hline \multirow{2}{*}{ Family and social } & Social service & 54 & 2.72 & .64628 \\
& Psychological counseling and educational & 72 & 3.06 & 1.02004 \\
& Child-rearing & 25 & 2.34 & .25187 \\
& Social service & 54 & 3.18 & .46891 \\
Factors media & Psychological counseling and educational & 72 & 3.52 & .88286 \\
& Child-rearing & 25 & 3.08 & .48648 \\
& Social service & 54 & 2.81 & .73404 \\
Religious factors & Psychological counseling and educational & 72 & 3.23 & 1.07415 \\
& Child-rearing & 25 & 2.90 & .67853 \\
& Social service & 54 & 3.70 & .70013 \\
\cline { 2 - 5 } & Psychological counseling and educational & 72 & 3.76 & .88704 \\
& Child-rearing & 25 & 3.00 & .36968 \\
\hline & Social service & 54 & 3.10 & .60797 \\
& Psychological counseling and educational & 72 & 3.39 & .90519 \\
& Child-rearing & 25 & 2.83 & .33241 \\
\hline
\end{tabular}

Notes from the Table (5) the existence of morphological differences between the averages and the presence of morphological differences between the averages of crimes of abuse against children in Jordan from the viewpoint of students Ajloun University College according to the variable of specialization, and to determine whether the differences between the averages are statistically significant at the level $(0.05 \geq)$ been applied to the analysis of variance (One way ANOVA), and analysis of variance results were as shown in Table (6) as follows: 
Table 11. Analysis of variance for the differences in the crimes of abuse against children in Jordan from the perspective of students Ajloun University College variable depending on the specialization

\begin{tabular}{lllllll}
\hline Domain & Source of variation & Sum of & Degrees of & Average & P value & The level of \\
\hline Family and social & Between groups & 10.486 & 2 & 5.243 & $* 7.956$ & 0.001 \\
factors & Within the groups & 97.533 & 148 & 0.659 & & \\
& Total & 108.02 & 150 & & & \\
Factors media & Between groups & 5.316 & 2 & 2.658 & $* 5.413$ & 0.005 \\
& Within the groups & 72.673 & 148 & 0.491 & & \\
\multirow{5}{*}{ Religious factors } & Total & 77.989 & 150 & & & \\
& Between groups & 6.098 & 2 & 3.049 & $* 3.713$ & 0.027 \\
& Within the groups & 121.527 & 148 & 0.821 & & \\
Psychological factors & Total & 127.624 & 150 & & & \\
& Between groups & 11.442 & 2 & 5.721 & $* 9.946$ & \multirow{2}{*}{0.027} \\
& Within the groups & 85.126 & 148 & 0.575 & & \\
Total score & Total & 96.568 & 150 & & & \\
& Between groups & 6.664 & 2 & 3.332 & $* 6.132$ & 0.003 \\
& Within the groups & 80.417 & 148 & 0.543 & & \\
\hline
\end{tabular}

Notes. * statistically significant

The results indicate in the Table (6) to the presence of statistically significant differences at the level $(0.05 \geq)$ in the crimes of abuse against children in Jordan from the perspective of students Ajloun University College, depending on the variable specialization on the tool as a whole and magazines subsidiary, in order to know the ownership of the difference was using Scheffe test for comparisons dimensional Table (7) below shows that.

Table 12. Scheffe test for a posteriori comparisons of the differences in the crimes of abuse against children in Jordan from the viewpoint of students Ajloun University College, variable Specialization

\begin{tabular}{|c|c|c|c|c|c|}
\hline Domain & Experience & SMA & Social & Psychological & Child- \\
\hline \multirow{3}{*}{$\begin{array}{l}\text { Family and } \\
\text { social factors }\end{array}$} & Social service & 2.72 & - & -.33449 & .38954 \\
\hline & Psychological counseling and educational & 3.06 & - & - & $.72403\left(^{*}\right)$ \\
\hline & Child-rearing & 2.34 & - & - & - \\
\hline \multirow{3}{*}{ Factors media } & Social service & 3.18 & - & $-.33889(*)$ & .09778 \\
\hline & Psychological counseling and educational & 3.52 & - & - & $.43667\left(^{*}\right)$ \\
\hline & Child-rearing & 3.08 & - & - & - \\
\hline Religious & Social service & 2.81 & - & $-.42593(*)$ & -.08859 \\
\hline \multirow[t]{2}{*}{ factors } & Psychological counseling and educational & 3.23 & - & - & .33733 \\
\hline & Child-rearing & 2.90 & - & - & - \\
\hline \multirow{3}{*}{$\begin{array}{l}\text { Psychological } \\
\text { factors }\end{array}$} & Social service & 3.70 & - & -.06389 & $.70000\left(^{*}\right)$ \\
\hline & Psychological counseling and educational & 3.76 & - & - & $.76389\left(^{*}\right)$ \\
\hline & Child-rearing & 3.00 & - & - & - \\
\hline \multirow{3}{*}{ Total score } & Social service & 3.10 & - & -.29080 & .27468 \\
\hline & Psychological counseling and educational & 3.39 & - & - & $.56548\left(^{*}\right)$ \\
\hline & Child-rearing & 2.83 & - & - & - \\
\hline
\end{tabular}

Notes. $\left(^{*}\right)$ Statistically significant difference 
Notes from the previous table:

(1) The difference for the field of family and social factors were allocated for the benefit of students psychological counseling where the average responses (3.06) when compared to the students of specialty child-rearing as the average responses (2.34).

(2) The difference for the field factors media was for the benefit of students allocated psychological counseling where the average responses (3.18) when compared to the students of specialty social service where the average responses (2.82). And for the benefit of students allocated psychological counseling where the average responses (3.18) when compared to the students of specialization child-rearing, where the average responses (2.81).

(3) The difference for the field of religious factors was allocated for the benefit of students psychological counseling where the average responses (3.06) when compared to the students of specialty social service where the average responses (3.08).

(4) The difference for the field of psychological factors was for the benefit of students allocated social service where the average responses (3.23) when compared to the students of specialty child-rearing as the average responses (3.03). And for the benefit of students of specialty child-rearing as the average responses (3.03) when compared to the students of specialization psychological counseling as the average responses (2.90)

(5) The difference for the total score (the tool as a whole) was allocated for the benefit of students psychological counseling where the average responses (3.76) when compared to the students of specialty child-rearing as the average responses (3.00).

Results fifth question: Are there any statistically significant differences in the significance level $(0.05)$ in the crimes of abuse against children in Jordan from the perspective of students Ajloun University College due to the variable age?

To answer this question were calculated averages and standard deviations crimes of abuse against children in Jordan from the perspective of students Ajloun University College variable depending on the age, the table shows (8) that.

Table 13. Averages and standard deviations in the crimes of abuse against children in Jordan from the perspective of students Ajloun University College, depending on the variable age

\begin{tabular}{lllll}
\hline Domain & Qualification & Number & SMA & SD \\
\hline \multirow{3}{*}{ Family and social factors } & Less than 20 years old & 54 & 2.72 & .65 \\
& 21-30 years & 72 & 3.06 & 1.02 \\
& More than 30 years & 25 & 2.34 & .25 \\
Factors Media & Less than 20 years old & 151 & 2.82 & .85 \\
& 21-30 years & 54 & 3.18 & .47 \\
& More than 30 years & 72 & 3.52 & .88 \\
Religious factors & Less than 20 years old & 60 & 2.4896 & .85473 \\
& 21-30 years & 36 & 3.5556 & .93084 \\
Psychological Factors & More than 30 years & 55 & 2.6977 & .37860 \\
& Less than 20 years old & 60 & 2.9367 & .59431 \\
& 21-30 years & 36 & 3.8778 & .92493 \\
Total Score & More than 30 years & 55 & 3.3818 & .35957 \\
& Less than 20 years old & 60 & 2.8067 & 1.05507 \\
& 21-30 years & 36 & 3.6278 & 1.06062 \\
\hline
\end{tabular}


Notes from the Table (8) the presence of morphological differences between the averages and the presence of morphological differences between the averages of crimes of abuse against children in Jordan from the viewpoint of students Ajloun University College according to the variable age, and to determine whether the differences between the averages are statistically significant at the level $(0.05 \geq)$ been applied to the analysis of variance (One way ANOVA), and analysis of variance results were as shown in Table (9) the following:

Table 14. Analysis of variance for the differences in the crimes of abuse against children in Jordan from the perspective of students Ajloun University College depending on the variable age

\begin{tabular}{lllllll}
\hline Domain & Source of variation & Sum of & Degrees of & Average & P value & The level of \\
\hline \multirow{2}{*}{ Family and social factors } & Between groups & 26.850 & 2 & 13.425 & $* 7.956$ & 0.001 \\
& Within the groups & 81.170 & 148 & .548 & & \\
& Total & 108.020 & 150 & & & \\
Factors Media & Between groups & 20.226 & 2 & 10.113 & & \\
& Within the groups & 57.763 & 148 & .390 & $* 5.413$ & 0.005 \\
& Total & 77.989 & 150 & & & \\
Religious factors & Between groups & 17.277 & 2 & 8.639 & & \\
& Within the groups & 110.347 & 148 & .746 & $* 3.713$ & 0.027 \\
& Total & 127.624 & 150 & & & \\
Psychological Factors & Between groups & 18.862 & 2 & 9.431 & & \\
& Within the groups & 77.706 & 148 & .525 & $* 9.946$ & 0.027 \\
& Total & 96.568 & 150 & & & \\
Total Score & Between groups & 19.368 & 2 & 9.684 & & \\
& Within the groups & 67.713 & 148 & .458 & $* 6.132$ & 0.003 \\
& Total & 87.081 & 150 & & & \\
\hline
\end{tabular}

Note. ${ }^{*}$ statistically significant

The results indicate in the Table (9) the presence of statistically significant differences at the level $(0.05 \geq)$ in the crimes of abuse against children in Jordan from the perspective of students Ajloun University College, depending on the variable age on the tool as a whole and all the magazines subsidiary, in order to know the ownership of the difference Scheffe test was used for comparisons dimensional Table (10) below shows that.

Table 15. Scheffe test for a posteriori comparisons of the differences in the development of creativity among teachers in public schools in Kuwait medium from the perspective of administrators and teachers, depending on the variable age

\begin{tabular}{llllll}
\hline Domain & Experience & SMA & Less than 20 & $21-30$ years & More than \\
\hline Family and social & Less than 20 years old & 2.72 & - & $-1.06597\left(^{*}\right)$ & -.20814 \\
factors & 21-30 years & 3.06 & - & - & $.85783\left(^{*}\right)$ \\
& More than 30 years & 2.34 & - & - & - \\
\multirow{5}{*}{ Factors Media } & Less than 20 years old & 2.82 & - & $-.94111\left(^{*}\right)$ & $-.44515\left(^{*}\right)$ \\
& 21-30 years & 3.18 & - & - & $.49596\left(^{*}\right)$ \\
Religious factors & More than 30 years & 3.52 & - & - & - \\
\hline
\end{tabular}




\begin{tabular}{llllll}
\hline & $21-30$ years & 3.59 & - & - & $.75869\left(^{*}\right)$ \\
& More than 30 years & 2.70 & - & - & - \\
\multirow{3}{*}{ Psychological Factors } & Less than 20 years old & 2.94 & - & $-.87889\left(^{*}\right)$ & $-.53545\left(^{*}\right)$ \\
& 21-30 years & 3.89 & - & - & .34343 \\
& More than 30 years & 3.38 & - & - & - \\
\multirow{3}{*}{ Total Score } & Less than 20 years old & 2.81 & - & $-.92677\left(^{*}\right)$ & $-.31279\left(^{*}\right)$ \\
& 21-30 years & 3.63 & - & - & $.61398(*)$ \\
& More than 30 years & 2.87 & - & - & - \\
\hline
\end{tabular}

(*) Statistically significant difference

\subsection{Notes from the Previous Table}

(1) The difference for the field of family and social factors were in favor of the age group less than 20 years where the average responses (3.06) when compared to age groups (21-30 years, more than 30 years old), where the average responses, respectively $(2.72 ; 2.34)$.

(2) The difference for the field of media factors were in favor of the age group 21-30 years, where the average responses (3.18) when compared to the age group less than 20 years where the average responses (2.82). And for the age group over 30 years as the average responses (3.52) when compared to the age group less than 20 years where the average responses (2.82).

(3) The difference for the field of religious factors were in favor of the age group 21-30 years, where the average responses (3.59) when compared to the age group less than 20 years where the average responses (2.49). And in favor of the age group 21-30 years, where the average responses (3.59) when compared to age group more than 30 years where the average responses (2.70).

(4) The difference for the field of psychological factors were in favor of the age group 21-30 years, where the average responses (3.89) when compared to the age group less than 20 years where the average responses (2.94). For the age group 21-30 years, where the average responses (3.89) when compared to the age group of more than 30 responses in terms that the average (3.38).

(5) The difference for the total score (the tool as a whole) was in favor of the age group 21-30 years, where the average responses (3.63) when compared to age groups (less than 20 years old; more than 30 years old), where the average responses, respectively $(2.81 ; 2.87)$. And in favor of the age group more than 30 years where the average responses (2.87) when compared to the age group less than 20 years where the average responses $(2.81)$.

\subsection{A Summary of the Main Results}

(1) With respect to family and social factors leading to sexual abuse against children, the results showed that the children left at home alone with the nanny and the lack of sex education is one of the most family and social factors, and the large number of family relationships lead to sex crimes against children. The average total score.

(2) With regard to the factors that are due to the media of the results showed that more factors are the misuse of the parents in front of children online, watch movies and exciting cultural sexually The average total score.

(3) With regard to religious factors results showed that the most important factors that lead to sexual abuse against children is twice the religious faith of young people who engage in abuse against children and religious factors that cause is mainly lack of attention to religious Baltncih inside the house and had an average total score.

(4) With regard to psychological factors and the individual results showed that the more psychological factors and individual depressive symptoms are associated with a teenager, and then having a positive personal characteristics of the aggressor on the child came in ranked last automatic suppression of feelings and emotions. Had an average total score.

(5) The results showed statistically significant differences in the significance level $(0.05 \geq)$ invaded the demographic variables on the answers of the study sample in all fields of study were as follows:

Variable sex was in favor of males

Qualification was variable for the benefit of undergraduate students 
Variable specialization was allocated for the benefit of students psychological counseling compared with social service specialty.

Variable life was in favor of the age group between 21/30 years compared to other categories.

\section{Recommendations}

(1) Increase awareness of domestic and sexual education of children working on the definition of sexual matters commensurate with their age and educational institutions, social assistant to this aspect in the first years of the child.

(2) Building places to protect and care for abused children, especially girls.

(3) Action seminars and lectures on the subject of sexual abuse against children and the media community awareness and to address this problem through attention to films and film culture of parental control.

(4) Liarits not take the child to his ignorance and leaving the offender without any accountability.

(5) To act with caution and keep his nerve and not take the threats of a child, a child in need of safety and calm and support so that he can face the faithful of disorders and problems.

(6) Teach a child how to choose the direction and people who can help him.

\section{References}

Al Saud, M. (2000). Child abuse, types, causes, and characteristics of the exposed him. Department of Social Studies, Faculty of Arts, King Saud University, Cairo, the Egyptian culture for the printing, publishing and distribution.

Algareeb, \& Abdul, A. (2007). Characteristics of social, economic and cultural rights of the families of the children exposed to abuse in Saudi society (Doctoral dissertation). Faculty of Social Sciences, University of Imam Muhammad bin Saud Islamic University, Riyadh.

Alrdian, K. (2008). Domestic violence against women. Cairo, Egypt.

Alsodi, A. M. (1993). The evolution of offenses against morality in Jordan. Department of Sociology, Faculty of Arts, University of Jordan.

Altnbari, F. A. R. (2003). Sexual harassment and its impact on children. The Graduate Institute for Childhood, Ain Shams University.

Badr, A. (2001). Sexual exploitation and physical abuse of children. Paper presented at the fourth annual conference, the National Center for Social and Criminological Research, Syria, Damascus.

Chen, J., Dunne, M. P., \& Han, P. (2006). Child sexual abuse in henan province, china: Associations with sadness, suicidality, and risk behaviors among adolescent girls. Journal of adolescent health, 38, 544-549. http://dx.doi.org/10.1016/j.jadohealth.2005.04.001

Figueiredo, B., Pavia, C., Maia, A., Fernandes, E., \& Matos, R. (2004). History of childhood abuse in Portuguese parents. Child abuse \& neglect, 28, 671-684. http://dx.doi.org/10.1016/j.chiabu.2003.11.021

Gladstone, G. G., Parker, G., Parker, P., Mitchell, G., Malhi, K., Wilhelm, M., \& Paula, A. (2004). Implications of childhood Trauma for Depressed women: An Analysis of pathways From childhood Sexual Abuse to deliberate self-Harm and Revictimization. The American Journal of Psychiatry, 161(8), 1417-2276. http://dx.doi.org/10.1176/appi.ajp.161.8.1417

Iman, M. (2005). Sexual harassment of children: Definitions, causes and prevention. Dar Pen Publishing and Distribution, Beirut.

Ismail, F. (2000). Child abuse: Scoping study for children beggars. Psychology, 14(53).

Jardan, A. (2005). The Promotion of Virtue and Prevention of Vice. Riyadh-Saudi Arabia.

Jishi, E. (2001). The reality of child abuse through the issues contained. Ministry of Interior, the Child Protection Conference of abuse and neglect by protecting Family and strengthen legislation, Bahrain.

Klark, R., \& Klark, J. (1989). The encyclopedia of child abuse. New York.

MacMillan, H. L., Jamieson, E., \& Walsh, C. A. (2003). Reported contact with child protection services among those reporting child physical and sexual abuse: Results from A community Survey. Child abuse \& neglect, 27, 1397-1408. http://dx.doi.org/10.1016/j.chiabu.2003.06.003

Mathoma, A. M., Maripe-perera, D. B., Khumalo, M. L. P., \& Seloilwe, B. L. (2006). Knowledge and perceptions of parents regarding child sexual abuse in botsment and Swaziland. Journal of pediatric nursing, 1, 67-72. http://dx.doi.org/10.1016/j.pedn.2005.08.002

Morsi, M. (2007). Child molestation. Education Magazine.

Mukhaimar, I., \& Abdel, R. I. (2004). The experience of abuse in childhood. Instruction manual. 
Obadah, M. D. K. (2007). The social dimensions of sexual harassment in everyday life, a field study in Sohag. Cairo, AL Center Alemraeh.

Poulakou-Rebwlakou, J. (2000). Child sexual abuse: Historical cases in the byzantine empire(324-1453 A.D). Child abuse \& neglect, 5, 1085-1090.

Rodgers, S. C., Lang, A. J., Laffaye, C., Satz, L. E., Dresselhaus, T. R. B., \& Stein, M. B. (2004). The impact of individual forms of childhood maltreatment on health behavior. Child abuse \& neglect, 5, 575-586. http://dx.doi.org/10.1016/j.chiabu.2004.01.002

Saeed, F. (2008). Detection rates of exposure to physical abuse and sexual abuse in childhood among juvenile delinquents compared to a particular officer of the non-delinquents. Journal of Arab Children, 34, 8-33.

Windham, A. M., Rosenberg, L., Fuddy, L., Mcfarlane, E. S., \& Duggan, A. K. (2004). Risk of mother-reported child abuse in the first 3 years of life. Child abuse \& neglect, 6, 647-669.

Wolf, D. (2005). Child abuse: Mitrtbaatha on child growth and psychological disturbance (S. Y. Juma Trans.). Cairo, publications Supreme Council of Culture/National Project for Translation.

Zahrani, A. (2005). Sexual abuse of children (Doctoral dissertation). Riyadh.

Zahrani, S. (2003). Child abuse in Saudi society. Riyadh, Crime Research Center.

\section{Copyrights}

Copyright for this article is retained by the author(s), with first publication rights granted to the journal.

This is an open-access article distributed under the terms and conditions of the Creative Commons Attribution license (http://creativecommons.org/licenses/by/3.0/). 